\title{
Effect of SKF-96365 on cardiomyocyte hypertrophy induced by angiotensin II
}

\author{
HUIJUN CHENG, JIAOXIA LI, QIYAN WU, XIAODONG ZHENG, YONGQIANG GAO, \\ QIAOFEN YANG, NINGXI SUN, MEIQIONG HE and YOUJUN ZHOU \\ Nuclear Medicine Department, Yan'an Hospital Affiliated to Kunming Medical University, \\ Kunming, Yunnan 650051, P.R. China
}

Received May 16, 2019; Accepted November 6, 2019

DOI: $10.3892 / \mathrm{mmr} .2019 .10877$

\begin{abstract}
Angiotensin II (Ang II) is an important bioactive peptide in the renin-angiotensin system, and it can contribute to cell proliferation and cardiac hypertrophy. Dysfunctions in transient receptor potential canonical (TRPC) channels are involved in many types of cardiovascular diseases. The aim of the present study was to investigate the role of the TRPC channel inhibitor SKF-96365 in cardiomyocyte hypertrophy induced by Ang II and the potential mechanisms of SKF-96365. $\mathrm{H} 9 \mathrm{c} 2$ cells were treated with different concentrations of Ang II. The expression levels of cardiomyocyte hypertrophy markers and TRPC channel-related proteins were also determined. The morphology and surface area of the H9c2 cells, the expression of hypertrophic markers and TRPC channel-related proteins and the $\left[{ }^{3} \mathrm{H}\right]$ leucine incorporation rate were detected in the Ang II-treated H9c2 cells following treatment with the TRPC channel inhibitor SKF-96365. The intracellular $\mathrm{Ca}^{2+}$ concentration was tested by flow cytometry. The present results suggested that the surface area of $\mathrm{H} 9 \mathrm{c} 2$ cells treated with Ang II was significantly increased compared with untreated $\mathrm{H} 9 \mathrm{c} 2$ cells. The fluorescence intensity of $\alpha$-actinin, the expression of hypertrophic markers and TRPC-related proteins, the $\left[{ }^{3} \mathrm{H}\right]$ leucine incorporation rate and the intracellular $\mathrm{Ca}^{2+}$ concentration were all markedly increased in the Ang II-treated H9c 2 cells but decreased following SKF-96365 treatment. The present results suggested that Ang II induced cardiomyocyte hypertrophy in $\mathrm{H} 9 \mathrm{c} 2$ cells and that the TRPC pathway may be involved in this process. Therefore, SKF-96365 can inhibit cardiomyocyte hypertrophy induced by Ang II by suppressing the TRPC pathway. The present results indicated that TRPC
\end{abstract}

Correspondence to: Dr Youjun Zhou, Nuclear Medicine Department, Yan'an Hospital Affiliated to Kunming Medical University, 245 East Renmin Road, Kunming, Yunnan 650051, P.R. China

E-mail: zhouyoujun_01@163.com

Key words: angiotensin II, SKF-96365, H9c2, cardiomyocyte hypertrophy, transient receptor potential canonical channels may be a therapeutic target for the development of novel drugs to treat cardiac hypertrophy.

\section{Introduction}

Cardiac hypertrophy is characterized by an increase in the volume of myocardial cells without cell division, resulting in increased protein accumulation in cells and increased formation of new sarcomeres and myofibrils. Cardiac hypertrophy induced by prolonged stress can lead to heart failure, which may increase the incidence and mortality rates of patients suffering from cardiovascular diseases (1). Therefore, understanding the mechanism of cardiac hypertrophy is important in the field of cardiovascular diseases. Compensatory hypertrophy after myocardial failure involves a series of complex events at the cellular and molecular levels that may lead to structural and functional changes in the myocardium (2). To the best of our knowledge, treatment of advanced heart failure consists primarily of palliative care. Therefore, understanding the signaling pathway involved in cardiomyocyte growth may provide new therapeutic targets for the treatment of cardiac hypertrophy.

Angiotensin II (Ang II) is an effector of the renin-angiotensin system, and it can increase blood pressure by inducing vasoconstriction via the activation of the angiotensin receptor system (3). An increasing number of studies have shown that Ang II serves an important role in cardiac hypertrophy in vitro and in vivo (4-7). The Ang II-mediated cardiomyocyte hypertrophy model has become an increasingly popular model to investigate cardiac hypertrophy $(8,9)$. The H9c2 cell line, an established cardiomyocyte cell line derived from embryonic rat ventricular tissue, is an important model for studying hypertension-induced cardiac hypertrophy (10). Therefore, the present study constructed a model of cardiomyocyte hypertrophy in H9c2 cells using Ang II treatment.

The transient receptor potential (TRP) channel gene was discovered in the visual transmission system of Drosophila (11). The trp mutation in Drosophila, which prevents $\mathrm{Ca}^{2+}$ signaling in the photoreceptors of Drosophila, results in transient spikes but not sustained spikes under continuous light stimulation $(12,13)$. According to amino acid sequence homology, the 28 mammalian TRP channels are divided into seven subfamilies: TRP canonical (TRPC), TRP 
ankyrin (TRPA), TRP melastatin (TRPM), TRP vanilloid (TRPV), TRP polycystin (TRPP), TRP no mechanoreceptor potential C (TRPN) and TRP mucolipin 7 (TRPML7) (14). The mammalian homologues that display the greatest similarity to the Drosophila TRP protein have been named TRP canonical channels (15). The TRPC subfamily consists of seven subtypes (TRPC1-TRPC7), which are generally composed of heteropolymers and are highly expressed in myocardial fibroblasts and myocardial cells (16). TRPC channels have six transmembrane domains, named S1-S6, and a nonselective cation channel is formed between the S5 and S6 segments at the $\mathrm{N}$-terminus, allowing cations such as calcium ions to pass through the cell membrane (17). The N-termini of TRPC channels have 3 or 4 anchoring protein-like repeat structures, which can regulate the release of calcium ions in the calcium pool by binding to the anchoring protein (18). TRPC channels are expressed in a number of organs, are important for organogenesis, and their dysfunction may result in organ damage (19). TRPC channel family members are the molecular basis of receptor-operated $\mathrm{Ca}^{2+}$ channels (ROCs) and store-operated $\mathrm{Ca}^{2+}$ channels (SOCs) on the cell membrane. TRPC3, TRPC6 and TRPC7 function as ROCs (20), and TRPC1, TRPC4 and TRPC5 function as SOCs (21-23).

$\mathrm{Ca}^{2+}$ plays a crucial role in maintaining cardiovascular physiological functions, such as cardiac contractility, hemodynamic stretching, expansion and repair (24). Malfunctions of TRPC channels are closely associated with a number of cardiovascular diseases $(25,26)$. Therefore, TRPC channels have been regarded as drug therapeutic targets for cardiac hypertrophy (27). A number of previous studies have demonstrated that the expression of TRPC1, TRPC5, TRPC6 and TRPC7 are markedly upregulated in cardiac hypertrophy, and accumulating evidence has demonstrated that TRPC channels are related to cardiac hypertrophy (28-31). Whether TRPC channels have a role in the development of cardiomyocyte hypertrophy, and whether TRPC channels are involved in the process of cardiomyocyte hypertrophy induced by Ang II remain unclear. In addition, the potential roles of TRPC channels in cardiomyocyte hypertrophy requires further investigation.

In the present study, the effects of three doses $(1,5$ and $10 \mu \mathrm{M})$ of SKF-96365, a non-selective TRPC inhibitor, on Ang II-induced cardiomyocyte hypertrophy were investigated in $\mathrm{H} 9 \mathrm{c} 2$ cells, and its possible mechanisms were examined.

\section{Materials and methods}

Cell culture. H9c2 cardiomyocytes were obtained from Chi Scientific, Inc., and cultured in complete high-glucose DMEM [cat. no. 06-1055-57-1ACS; Biological Industries (BI)] with 10\% FBS (cat. no. 04-001-1ACS; BI) and 1\% penicillin/streptomycin (cat. no. 03-031-1B; BI). The cells were incubated with $5 \% \mathrm{CO}_{2}$ at $37^{\circ} \mathrm{C}$.

Establishment of cardiomyocyte hypertrophy. The cells were divided into four groups: i) The $0 \mu \mathrm{M}$ Ang II group (control); ii) the $0.01 \mu \mathrm{M}$ Ang II group; iii) the $0.1 \mu \mathrm{M}$ Ang II group; and iv) the $1 \mu \mathrm{M}$ Ang II group. After treatment for $72 \mathrm{~h}$, the cells were collected to detect the protein expression levels of two factors associated with cardiomyocyte hypertrophy, such as atrial natriuretic peptide (ANP) and $\alpha$-actinin, by western blot assay. The optimal concentration to induce cell hypertrophy in subsequent experiments was selected as $0.1 \mu \mathrm{M}$ because it induced the highest expression of ANP and $\alpha$-actinin compared with the other concentrations.

Drug treatment. H9c2 cells were divided into five groups: i) The control group; ii) the $0.1 \mu \mathrm{M}$ Ang II group; iii) the $0.1 \mu \mathrm{M}$ Ang II $+1 \mu \mathrm{M}$ SKF-96365 group; iv) the $0.1 \mu \mathrm{M}$ Ang II $+5 \mu \mathrm{M}$ SKF-96365 group; and v) the $0.1 \mu \mathrm{M}$ Ang II+10 $\mu$ M SKF-96365 group. The cells were pretreated with SKF-96365 for $30 \mathrm{~min}$ and subsequently treated with Ang II for an additional $72 \mathrm{~h}$. SKF-96365 was purchased from Selleck Chemicals (cat. no. S7999).

Measurement of cell surface area. Cells were digested into a cell suspension by $0.25 \%$ trypsin for $30 \mathrm{sec}$ at $37^{\circ} \mathrm{C}$, and the degree of digestion was controlled to avoid cell shrinkage. A total of five fields were randomly selected for each group, and 20 cells were randomly selected from each field for imaging. The cell surface area $\left(\mu \mathrm{m}^{2}\right)$ was measured using ImageJ $2 \mathrm{x}$ software (Rawak Software, Inc.), and the mean value was calculated.

Detection of protein synthesis rate. The protein synthesis rate of cells in all groups was determined by a $\left[{ }^{3} \mathrm{H}\right]$ leucine incorporation assay (8). The cultured cells were treated with a $\left[{ }^{3} \mathrm{H}\right]$ leucine isotope marker (GE Healthcare Life Sciences) $12 \mathrm{~h}$ before the test. The medium was removed, and the cells were rinsed twice with PBS. The cells were digested with $0.25 \%$ trypsin and repeatedly agitated for $4 \mathrm{~min}$ to detach the cells. The cell suspension was added to a glass fiber filter membrane to remove the liquid, dried and fixed with 5\% trichloroacetic acid for $30 \mathrm{~min}$ at $4^{\circ} \mathrm{C}$, and the free isotope markers were washed away. The membrane was dried and placed in a $5 \mathrm{ml}$ flask with scintillation solution. The radioactive intensity was detected by a liquid scintillation counter (MicroBeta; PerkinElmer, Inc.). The data are expressed as counts/min.

Measurement of intracellular $\mathrm{Ca}^{2+}$ concentration. Cells were cultured in special confocal dishes and washed with PBS 2-3 times. Then, cells were treated with $100 \mu \mathrm{l}$ of a $5 \mu \mathrm{M}$ Fluo-4/AM calcium fluorescent probe solution (Beyotime Institute of Biotechnology), and were incubated at $37^{\circ} \mathrm{C}$ for $30 \mathrm{~min}$. After incubation, the cells were washed with PBS 2-3 times, and $1 \mathrm{ml}$ PBS was added to the cells. The Fluo-4/AM positive cells were detected by flow cytometry (Sysmex Partec $\mathrm{GmbH}$ ) at an excitation wavelength of $488 \mathrm{~nm}$ and an emission wavelength of $512-520 \mathrm{~nm}$. The fluorescence intensity of the cells was also quantitatively analyzed using FlowMax version 2.8 flow cytometry software (Sysmex Partec GmbH).

Reverse transcription-quantitative PCR (RT-qPCR) assay. The expression of ANP, nuclear factor of activated T-cells (NFAT), $\alpha$-actinin, $\beta$-myosin heavy chain (MHC), TRPC3 and TRPC6 at the mRNA level was determined by RT-qPCR assay. Total RNA was obtained by TRIzol ${ }^{\circledR}$ reagent (Invitrogen; Thermo Fisher Scientific, Inc.). The RNA concentration was measured by a Nanodrop 2000 (Thermo Fisher Scientific, Inc.). Then, cDNA was synthesized from the total RNA with 
PrimeScript RT Mix Kit (Takara Bio, Inc.) at $37^{\circ} \mathrm{C}$ for $15 \mathrm{~min}$ and then $85^{\circ} \mathrm{C}$ for $5 \mathrm{sec}$. The cDNA was amplified with SYBR Green PCR Mix (Thermo Fisher Scientific, Inc.) and an ABI 7300 system (Thermo Fisher Scientific, Inc.). The following thermocycling conditions were used for the qPCR: Initial denaturation, $95^{\circ} \mathrm{C}$ for $10 \mathrm{~min}$; followed by 40 cycles of $95^{\circ} \mathrm{C}$ for $15 \mathrm{sec}$ and $60^{\circ} \mathrm{C}$ for $60 \mathrm{sec}$. The expression levels were normalized to that of GAPDH. The primers for qPCR are as follows: TRPC3-forward (F), 5'-TGTGGTCTGAGTGCAAGG AG-3' and TRPC3-reverse (R), 5'-ACCTCTGGTGGGAGT GTGAC-3'; TRPC6-F, 5'-TTTGCTGAAGGCAAGAGGTT-3' and TRPC6-R, 5'-TTGTTTCTGGCTGCATTCTG-3'; ANP-F, 5'-ATACAGTGCGGTGTCCAACA-3' and ANP-R, 5'-CGA GAGCACCTCCATCTCTC-3'; brain natriuretic peptide (BNP)-F, 5'-GGAAATGGCTCAGAGACAGC-3' and BNP-R, 5'-CGATCCGGTCTATCTTCTGC-3'; $\beta$-MHC-F, 5'-CCT CGCAATATCAAGGGAAA-3' and $\beta$-MHC-R, 5'-TACAGG TGCATCAGCTCCAG-3'; GAPDH-F, 5'-CTCATGACCACA GTCCATGC-3' and GAPDH-R, 5'-TTCAGCTCTGGGATG ACCTT-3'.

Western blotting assay. Protein was extracted with RIPA lysis buffer (Beyotime Institute of Biotechnology). Total protein was quantified using a Bicinchoninic Acid Assay kit (Beyotime Institute of Biotechnology). A total of $40 \mu \mathrm{g}$ of protein was used for $10 \%$ SDS-PAGE and transferred to PVDF membranes. Subsequently, the membranes were blocked with $5 \%$ skim milk at $4^{\circ} \mathrm{C}$ overnight. The membranes were incubated with the following primary antibodies overnight at $4^{\circ} \mathrm{C}$ : anti-ANP (1:1,000; cat. no. A14755; ABclonal Biotech Co., Ltd.), anti-NFAT2 (1:1,000; cat. no. A1539; ABclonal Biotech Co., Ltd.), anti- $\alpha$-actinin (1:1,000; cat. no. sc-17829; Santa Cruz Biotechnology, Inc.), anti- $\beta-$ MHC $(1: 1,000$; cat. no. A7564; ABclonal Biotech Co., Ltd.), anti-TRPC3 (1:1,000; cat. no. A7742; ABclonal Biotech Co., Ltd.), anti-TRPC6 (1:1,000; cat. no. bs-2393R; BIOSS) and anti-GAPDH (1:2,000; cat. no. AC033; ABclonal Biotech Co., Ltd.). Subsequently, the membranes were incubated with a horseradish peroxidase (HRP) conjugated goat anti-rabbit immunoglobulin (Ig)G secondary antibody (1:5,000; cat. no. bs-0295G-HRP; BIOSS) or HRP-conjugated goat anti-mouse IgG secondary antibody (1:5,000; cat. no. AS003; ABclonal Biotech Co., Ltd.) for $2 \mathrm{~h}$ at room temperature. The membranes were detected with Immobilon Western HRP substrate (EMD Millipore). The bands were semi-quantified by ImageJ $2 x$ software (Rawak Software, Inc.).

Immunofluorescence assay. A total of $1 \times 10^{5}$ cells were seeded in 6-well plates. After treatment, the cells were fixed in $4 \%$ paraformaldehyde (PFA) for $30 \mathrm{~min}$ at room temperature, permeabilized with $0.2 \%$ Triton $\mathrm{X}-100$ for $5 \mathrm{~min}$ at room temperature and then blocked with 5\% BSA for $30 \mathrm{~min}$ at room temperature. Then, the cells were incubated with the $\alpha$-actinin antibody (1:100) in PBS, a FITC-conjugated goat anti-mouse IgG antibody (1:50; cat. no. AS001; ABclonal Biotech Co., Ltd.) for $30 \mathrm{~min}$ at room temperature, and DAPI (Beyotime Institute of Biotechnology) for $5 \mathrm{~min}$ at room temperature. The cells from the different groups were observed by fluorescence microscopy (magnification, x200; Nikon Corporation).
Statistical analysis. Data are presented as the mean \pm SD. Statistical analysis was determined by one-way ANOVA, followed by Tukey's multiple comparisons test with GraphPad Prism software (version 5.0a; GraphPad Software, Inc.). $\mathrm{P}<0.05$ was considered to indicate a statistically significant difference.

\section{Results}

Cardiomyocyte hypertrophy markers $A N P$ and $\alpha$-actinin are increased after Ang II treatment, and TRPC channels are involved in this process. The effect of Ang II on the cardiomyocyte hypertrophy markers ANP and $\alpha$-actinin in H9c2 cells was detected by western blot assay. As shown in Fig. 1A, Ang II $(0.01$ and $0.1 \mu \mathrm{M})$ significantly promoted the protein expression levels of ANP and $\alpha$-actinin. The semi-quantitative results of the western blot assay identified that the expression levels of ANP and $\alpha$-actinin were the highest after treatment with $0.1 \mu \mathrm{M}$ Ang II (Fig. 1B and C). According to the results of the western blot analysis, the expression levels of TRPC3 3 and TRPC6 were higher in the Ang II-treated groups compared with the control group, and their expression levels were higher in the $0.1 \mu \mathrm{M}$ Ang II-treated group than in the $0.01 \mu \mathrm{M}$ Ang II-treated group. However, there was no difference between the $0.1 \mu \mathrm{M}$ Ang II-treated group and the $1 \mu \mathrm{M}$ Ang II-treated group (Fig. 1A, D and E). The present results indicated that TRPC channels may be associated with the process of Ang II-induced cardiomyocyte hypertrophy in H9c2 cells. Moreover, $0.1 \mu \mathrm{M}$ Ang II for $72 \mathrm{~h}$ was the optimal concentration for the induction of cardiomyocyte hypertrophy markers ANP and $\alpha$-actinin in $\mathrm{H} 9 \mathrm{c} 2$ cells.

SKF-96365 inhibits the expression levels of TRPC3, TRPC6 and cardiomyocyte hypertrophy marker genes in Ang-II-treated $\mathrm{H} 9 \mathrm{c} 2$ cells. To determine the inhibitory role of the TRPC channel inhibitor SKF-96365 on cardiomyocyte hypertrophy in H9c2 cells treated with Ang-II, the expression levels of two genes encoding for TRPC channels, TRPC 3 and TRPC6, and the cardiomyocyte hypertrophy markers ANP, $\mathrm{BNP}$, and $\beta$-MHC by qPCR and western blotting. As shown in Fig. 2A, the present qPCR results showed that SKF-96365 significantly suppressed the increased expression of TRPC3, TRPC6, ANP, BNP and $\beta$-MHC induced by Ang II. The western blot results were consistent with the qPCR results (Fig. 2B and C). These results suggested that SKF-96365 suppressed the expression levels of cardiomyocyte hypertrophy markers in Ang II-treated H9c2 cells.

SKF-96365 inhibits Ang II-induced cardiomyocyte hypertrophy. To demonstrate the potential inhibitory role of SKF-96365 in cardiomyocyte hypertrophy induced by Ang II, the protein level of $\alpha$-actinin was examined by immunofluorescence. In addition, the H9c2 cell surface area and the $\left[{ }^{3} \mathrm{H}\right]$ leucine incorporation rate were investigated in all groups. As shown in Fig. 3, H9c2 cardiomyocytes were attached and exhibited a triangular or irregular shape, and the $\alpha$-actinin protein was localized in the cytoplasm. Ang II $(0.1 \mu \mathrm{M})$ markedly increased the size of the cardiomyocytes and the level of $\alpha$-actinin. However, SKF-96365 markedly decreased the size of the cardiomyocytes and the level of 
A

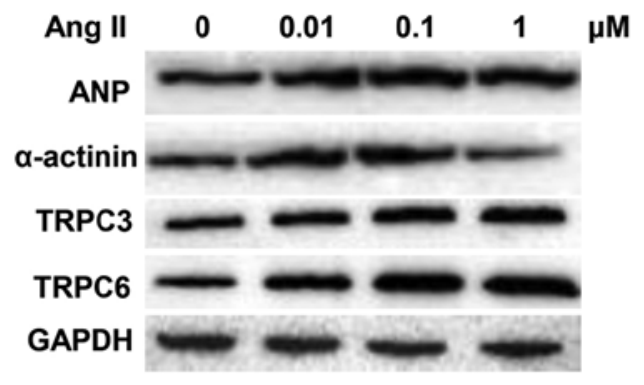

B

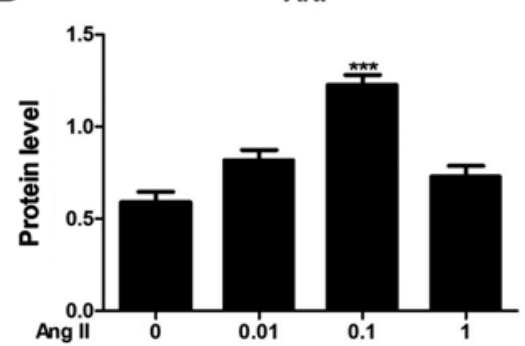

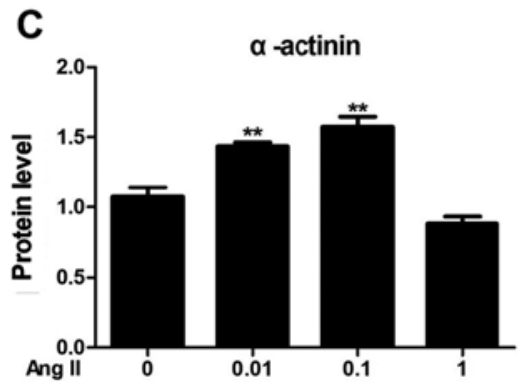

D

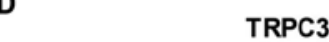

\section{E}
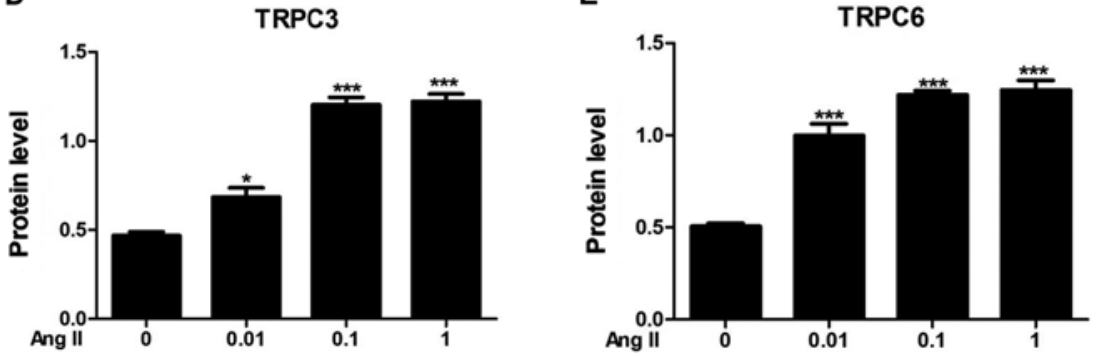

Figure 1. Ang II induces the protein expression levels of ANP, $\alpha$-actinin, TRPC3 and TRPC6 in H9c2 cells. (A) Protein levels of ANP, $\alpha$-actinin, TRPC3 and TRPC6 in H9c2 cells treated with different concentrations of Ang-II were detected by western blotting. (B-E) Relative semi-quantitative analysis of (B) ANP, (C) $\alpha$-actinin, (D) TRPC3 and (E) TRPC6 protein expression in all groups. ${ }^{*} \mathrm{P}<0.05,{ }^{* *} \mathrm{P}<0.01,{ }^{* * *} \mathrm{P}<0.001$ vs. $0 \mu \mathrm{M}$ group. Ang II, angiotensin II; ANP, atrial natriuretic peptide; TRPC, transient receptor potential canonical.
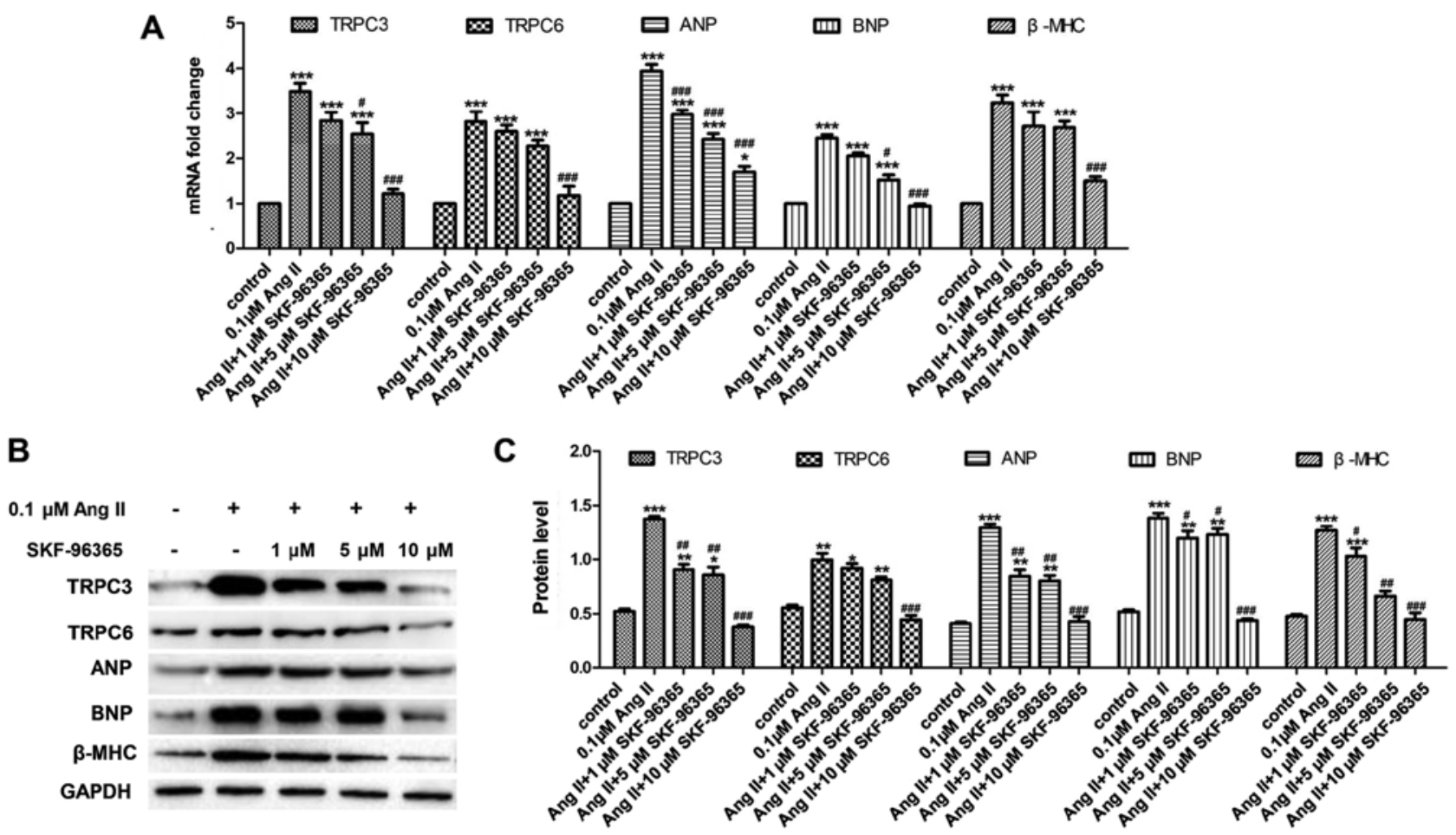

Figure 2. SKF-96365 inhibits the increase in expression levels of TRPC3, TRPC6, ANP, BNP and $\beta$-MHC induced by Ang II treatment. TRPC3, TRPC6, ANP, BNP and $\beta$-MHC mRNA levels in H9c2 cells treated with different concentrations of SKF-96365 were detected by (A) quantitative PCR and (B) western blotting. (C) Relative semi-quantitative analysis of TRPC3, TRPC6, ANP, BNP and $\beta$-MHC protein expression in all groups. ${ }^{*} \mathrm{P}<0.05$, ${ }^{* *} \mathrm{P}<0.01,{ }^{* * * *} \mathrm{P}<0.001 \mathrm{vs}$. control group; ${ }^{\#} \mathrm{P}<0.05,{ }^{\# \#} \mathrm{P}<0.01,{ }^{\# \# / t} \mathrm{P}<0.001$ vs. $0.1 \mu \mathrm{M}$ Ang II group. Ang II, Angiotensin II; ANP, atrial natriuretic peptide; BNP, brain natriuretic peptide; $\beta$-MHC, $\beta$-myosin heavy chain; TRPC, transient receptor potential canonical.

$\alpha$-actinin in a dose-dependent manner (Figs. 3 and 4). These results suggested that the TRPC channel inhibitor SKF-96365 may suppress Ang II-induced cardiomyocyte hypertrophy. As shown in Fig. $4 \mathrm{~A}$ and $\mathrm{B}$, Ang II $(0.1 \mu \mathrm{M})$ increased the surface area of H9c2 cells, and SKF-96365 significantly attenuated the increased surface area of $\mathrm{H} 9 \mathrm{c} 2$ cells induced by Ang II. Ang II $(0.1 \mu \mathrm{M})$ also induced an increase in the $\left[{ }^{3} \mathrm{H}\right]$ leucine incorporation rate compared with the control group, but SKF-96365 


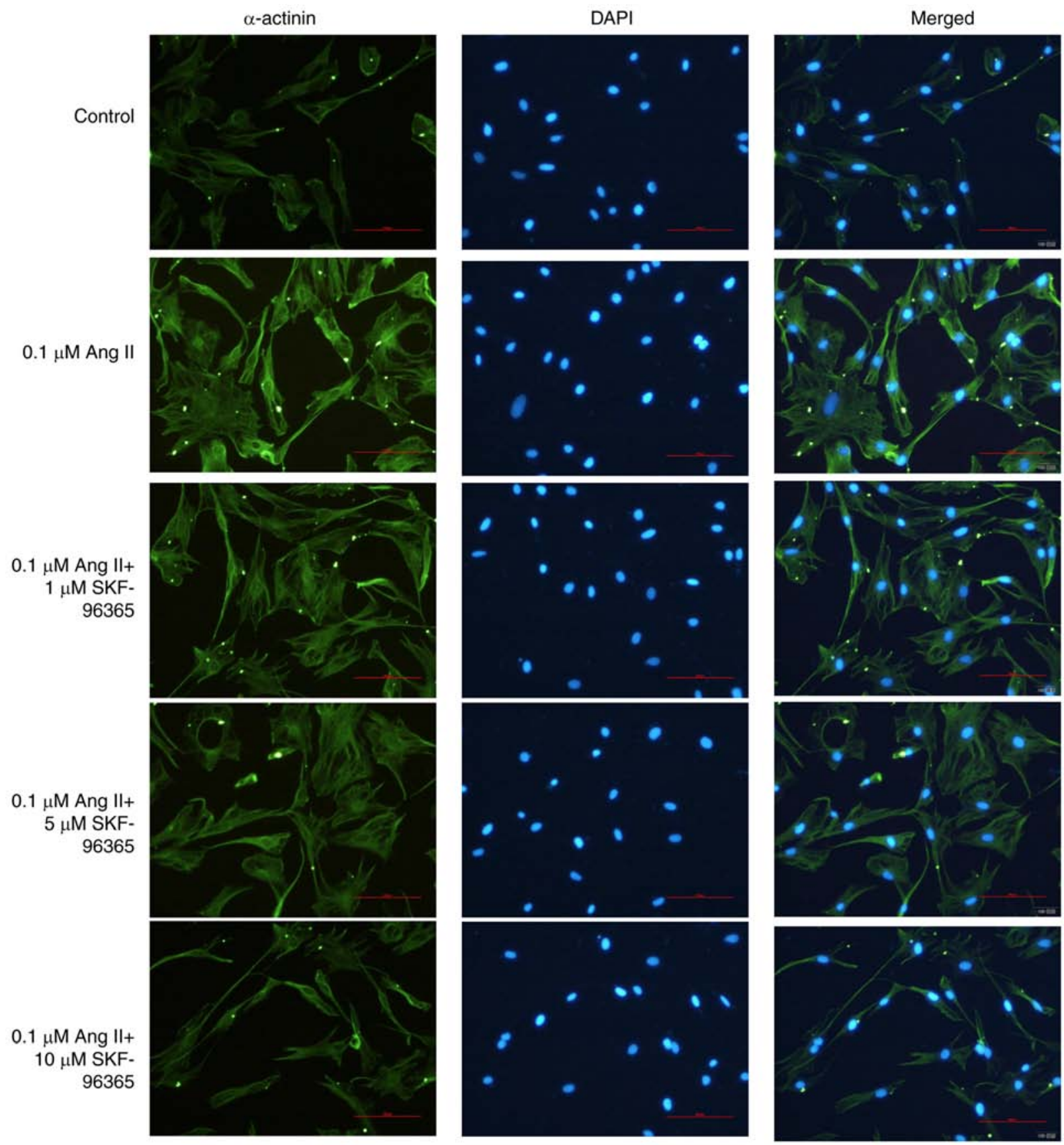

Figure 3. SKF-96365 inhibits $\alpha$-actinin expression treated with Ang II and affects the morphology of H9c2 cells. Morphology of H9c2 cells in the control group and $\alpha$-actinin immunofluorescence staining (magnification, x200). Scale bar, $100 \mu \mathrm{m}$. H9c2 cells treated with Ang II appear to be more hypertrophic. $\alpha$-actinin was localized to the cytoplasm of the H9c2 cells. Ang II, Angiotensin II.

inhibited the increased $\left[{ }^{3} \mathrm{H}\right]$ leucine incorporation rate induced by Ang II in a dose-dependent manner (Fig. 4C). The present results suggested that blocking TRPC channels inhibited cardiomyocyte hypertrophy induced by Ang II.

SKF-96365 inhibits Ang II-induced intracellular $\mathrm{Ca}^{2+}$ rise. The effect of SKF-96365 on the Ang II-induced $\mathrm{Ca}^{2+}$ increase was determined using the $\mathrm{Ca}^{2+}$ indicator Fluo-4/AM and flow cytometry. The Fluo-4 percentage is an indicator of the intracellular $\mathrm{Ca}^{2+}$ concentration. Ang-II $(0.1 \mu \mathrm{M})$ significantly increased the intracellular $\mathrm{Ca}^{2+}$ concentration compared with the control group, but SKF-96365 inhibited the increased $\mathrm{Ca}^{2+}$ concentration induced by Ang-II in a dose-dependent manner
(Fig. 5A). In addition, the $\mathrm{Ca}^{2+}$ levels were quantified by flow cytometry (Fig. 5B).

\section{Discussion}

Pathological myocardial hypertrophy, defined as myocardial cell enlargement and cardiac systolic dysfunction, is a risk factor for cardiovascular diseases, and may cause severe arrhythmia and heart failure $(32,33)$. However, the molecular mechanisms involved in cardiac hypertrophy are still unclear. In the present study, the effects of SKF-96365, a nonselective TRPC inhibitor, on Ang II-induced cardiomyocyte hypertrophy were investigated in $\mathrm{H} 9 \mathrm{c} 2$ cells. 
A
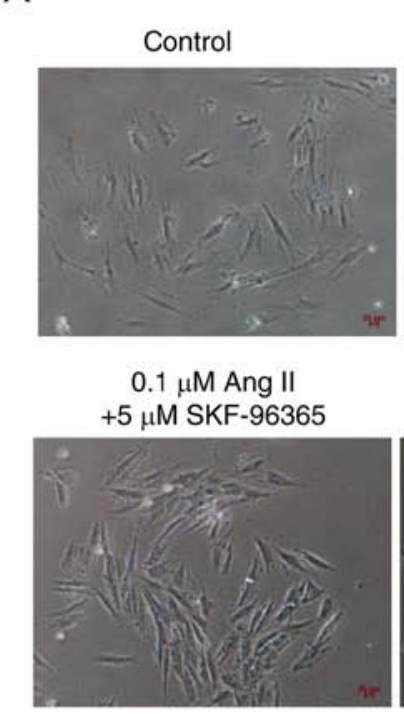

$0.1 \mu \mathrm{M}$ Ang II

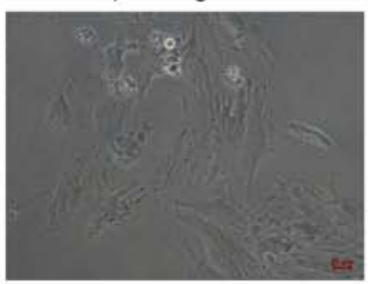

$0.1 \mu \mathrm{M}$ Ang II $+10 \mu \mathrm{M}$ SKF-96365

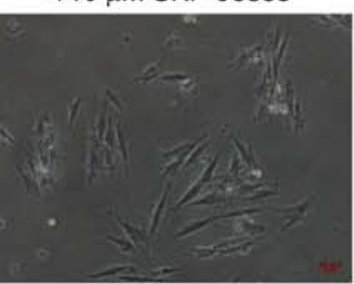

B

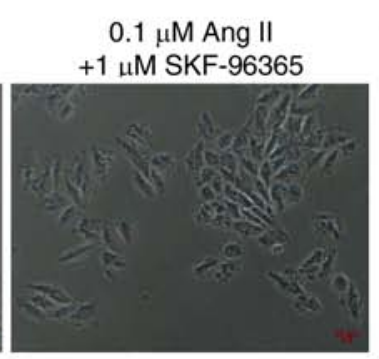

है

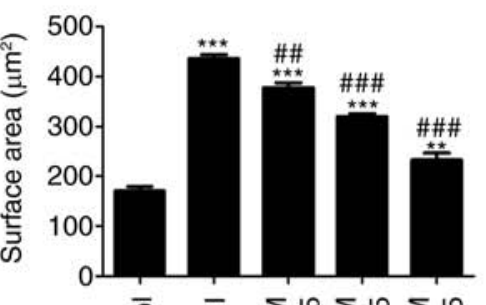

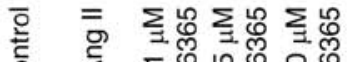

రิ

C

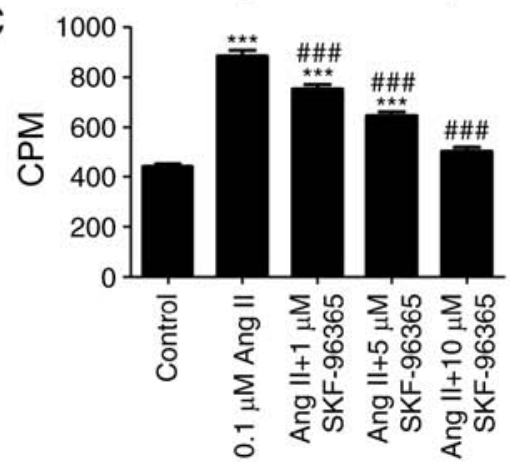

Figure 4. Effects of SKF-96365 on cell surface area and protein synthesis rate in Ang II-treated H9c2 cells. (A) Bright field images for each group (magnification, x200). Scale bars, $20 \mu \mathrm{m}$. (B) $\left[{ }^{3} \mathrm{H}\right]$ leucine incorporation rate in each group. (C) Cell surface areas were calculated using ImageJ software. ${ }^{* *} \mathrm{P}<0.01$, ${ }^{* * * *} \mathrm{P}<0.001$ vs. control group; ${ }^{\# \#} \mathrm{P}<0.01,{ }^{\# \# \#} \mathrm{P}<0.001$ vs. $0.1 \mu \mathrm{M}$ Ang II group. Ang II, angiotensin II; CPM, counts per minute.

The TRP family is a superfamily of nonselective cation-permeable channels that have a crucial role in the pathophysiological process of various diseases (34-36). According to amino acid sequence homology, the mammalian TRP channel superfamily has been divided into seven subfamilies: TRPC, TRPM, TRPA, TRPV, TRPP, TRPML and TRPN (37). TRPC channels mediate $\mathrm{Ca}^{2+}$ influx controlled by the calcium reservoir (38). Previous studies have found that the TRPC family is associated with the regulation of tumor growth, invasion and metastasis $(39,40)$, is involved in the occurrence and development of central nervous system diseases (41), and plays a role in primary hypertension and myocardial cell apoptosis (42). It has been reported that miR-103 exerts an inhibitory effect on cardiac hypertrophy by reducing cardiac autophagy through TRPV3 (43). TRPA1 inhibition can ameliorate cardiac hypertrophy and fibrosis induced by increased blood pressure in mice (44). In addition, TRPC1 knockdown protects heart function and morphology in mouse models of pressure overload (45). Moreover, the inhibition of TRPC6 has antihypertrophic results on the activity of the cardiac ANP/BNP-GC-A pathway (46). In the present study, the inhibition of TRPC channels suppressed the hypertrophy of $\mathrm{H} 9 \mathrm{c} 2$ cells induced by Ang II by decreasing the concentration of $\mathrm{Ca}^{2+}$. Accumulating evidence has indicated that TRPC channels have a pivotal function in the process of cardiac hypertrophy $(47,48)$.

SKF-96365 is a non-selective TRPC channel blocker (49). It was first recommended as an inhibitor of ionotropic receptor-mediated $\mathrm{Ca}^{2+}$ entry (50). A previous study reported that SKF-96365 suppresses voltage-gated sodium currents in rat ventricular myocytes (51). The present results show that SKF-96365 strongly reduces the $\mathrm{Ca}^{2+}$ concentration.
Ang II serves an important role in promoting the hypertrophy of myocardial cells, which can increase myocardial cell volume and total protein content, without affecting the number of cells $(52,53)$. Previous studies have indicated that Ang II directly regulates myocardial contractility and hypertrophic growth (54). The present results suggest that Ang II induced high levels of TRPC 3 and TRPC6 in H9c2 cells. A previous study showed that TRPC 3 and TRPC6 are crucial for Ang II-induced cardiac hypertrophy (55), consistent with the present results. Harada et al (56) found that TRPC3 is highly expressed in freshly harvested rat cardiac fibroblasts and that pyrazole-3, as a selective TRPC 3 channel blocker, inhibits Ang II-induced calcium ion flow, thus reducing fibroblast proliferation. The present results indicated that SKF-96365, a nonselective TRPC inhibitor, suppressed cardiomyocyte hypertrophy markers and TRPC 3 and TRPC6 expression. In a previous study, Gao et al (57) demonstrated that Nifedipine is more efficient than SKF-96365 at blocking $\mathrm{Ca}^{2+}$ influx and cardiac hypertrophy. Because this previous study focused on the source of hypertrophic $\mathrm{Ca}^{2+}$, the Nifedipine (L-type $\mathrm{Ca}^{2+}$ channel antagonist), SKF-96365 (TRP channel antagonist) and Nickel (T-type $\mathrm{Ca}^{2+}$ channel antagonist) were chosen to reduce the levels of $\mathrm{Ca}^{2+}$. The present study aimed to investigate the role of a TRPC channel inhibitor in cardiomyocyte hypertrophy induced by Ang II. Therefore, the TRPC channel inhibitor SKF-96365 was selected to block the TRPC channel pathway. SKF-96365 was initially used as a $\mathrm{Ca}^{2+}$ blocker; however, it was later used as a TRPC channel blocker (58). In the present study, the role of SKF-96365 was investigated in myocardial hypertrophy, and the present results provided a theoretical basis for the use of SKF-96365 in clinical practice. 
A

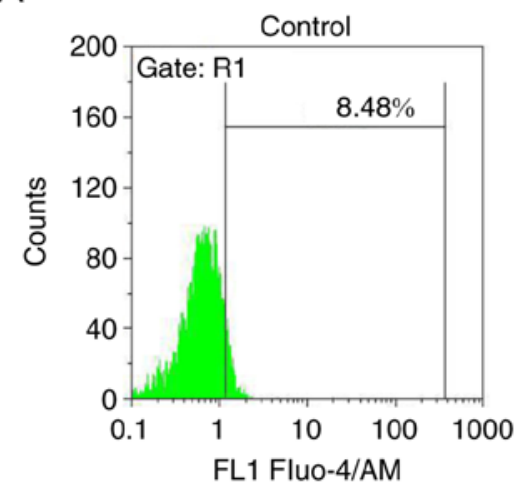

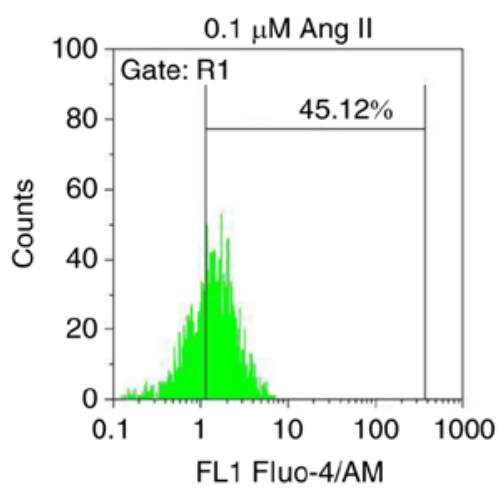
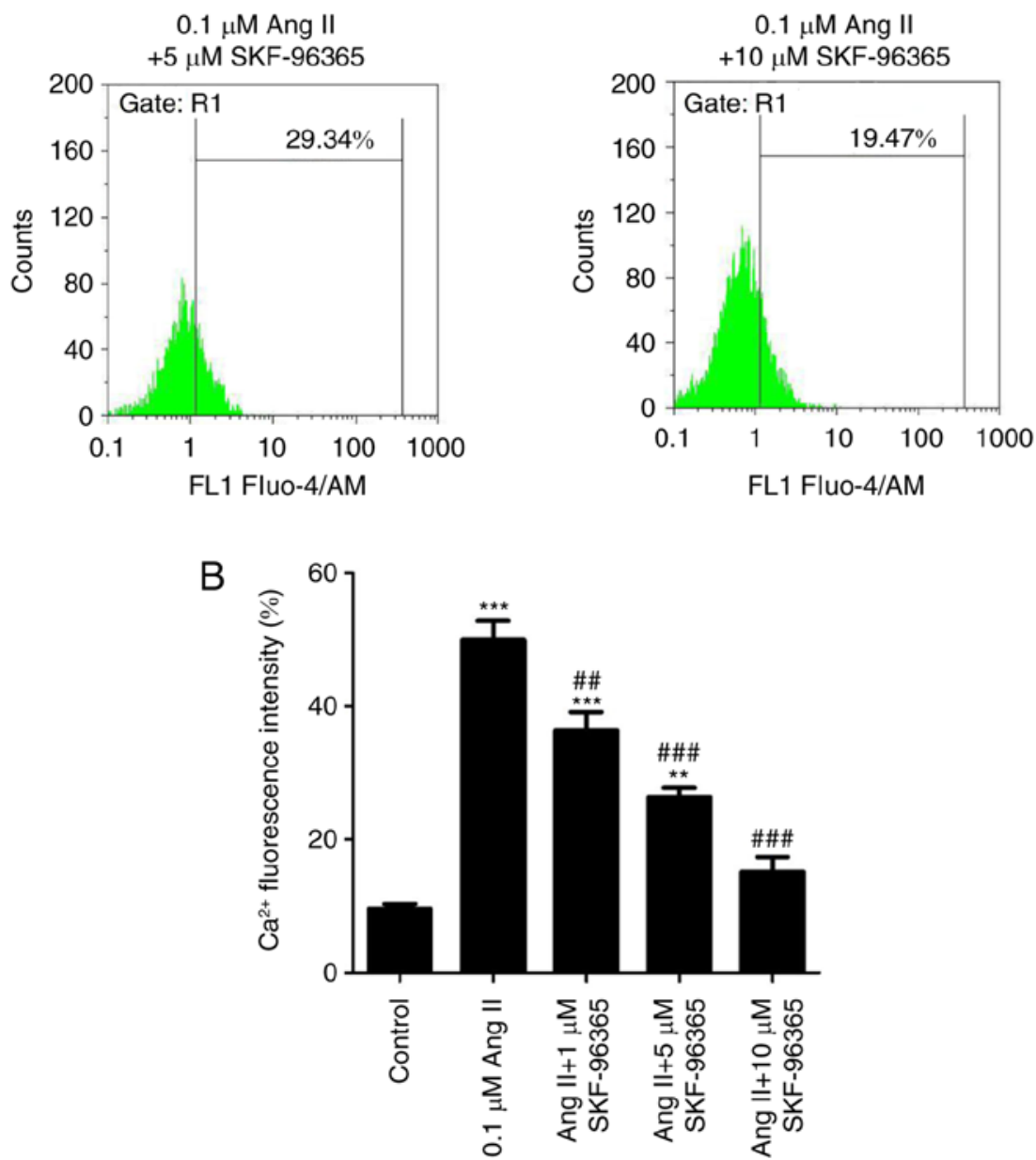

Figure 5. Effects of SKF-96365 on the intracellular $\mathrm{Ca}^{2+}$ fluorescence content in Ang II-treated H9c2 cells. (A) Flow cytometry results in all groups. (B) Quantitative analysis of the flow cytometry results. ${ }^{* *} \mathrm{P}<0.01,{ }^{* * * *} \mathrm{P}<0.001$ vs. control group; ${ }^{\# \#} \mathrm{P}<0.01,{ }^{\# \# "} \mathrm{P}<0.001$ vs. $0.1 \mu \mathrm{M}$ Ang II group. Ang II, angiotensin II.

In the present study a cardiomyocyte hypertrophy model was established using $\mathrm{H} 9 \mathrm{c} 2$ cells treated with $0.1 \mu \mathrm{M}$ Ang II. After treatment with 1,5 or $10 \mu \mathrm{M}$ SKF-96365, the expression levels of various cardiomyocyte hypertrophy markers were investigated, including ANP, BNP, and $\beta$-MHC, and the TRPC channel-related genes TRPC3 and TRPC6 were investigated. In addition, the fluorescence intensity of $\alpha$-actinin, the cell surface area, the protein synthesis rate, and the intracellular $\mathrm{Ca}^{2+}$ concentration were examined. SKF-96365 was found to decrease the expression levels of ANP, BNP, $\beta$-MHC, TRPC 3 and TRPC6 induced by Ang II in a dose-dependent manner. SKF-96365 significantly suppressed the increased cell surface area and the protein synthesis rate induced by Ang II. Furthermore, the intracellular $\mathrm{Ca}^{2+}$ concentration was decreased by SKF-96365 treatment. The present data suggested that SKF-96365 inhibited Ang II-induced cardiomyocyte hypertrophy by decreasing the intracellular $\mathrm{Ca}^{2+}$ concentration. Therefore, the non-selective TRPC inhibitor SKF-96365 may be considered as a potential treatment for myocardial hypertrophy.

\section{Acknowledgements}

Not applicable. 


\section{Funding}

This work was supported by the Special Project of Yunnan Science and Technology Department-Kunming Medical University Applied Basic Research [grant no. 2017FE467(-095)] and the Open Subject of Key Laboratory of Cancer Immune Prevention and Control in Yunnan Province (grant no. 2017DG004-06).

\section{Availability of data and materials}

The datasets used and/or analyzed during the current study are available from the corresponding author on reasonable request.

\section{Authors' contributions}

HC, JL and YZ conceived and designed the study. QW, XZ, YG, QY, NS and MH performed the experiments. HC, JL, XZ, QW and QY analyzed the data. YZ, HC, XZ and YG wrote the manuscript. YZ and $\mathrm{HC}$ reviewed and edited the manuscript. All authors read and approved the manuscript.

\section{Ethics approval and consent to participate}

Not applicable.

\section{Patient consent for publication}

Not applicable.

\section{Competing interests}

The authors declare that they have no competing interests.

\section{References}

1. Messerli FH, Aristizabal D and Soria F: Reduction of left ventricular hypertrophy: How beneficial Am Heart J 125: $1520-1524,1993$

2. Oka T, Akazawa H, Naito AT and Komuro I: Angiogenesis and cardiac hypertrophy: Maintenance of cardiac function and causative roles in heart failure. Circ Res 114: 565-571, 2014.

3. Ito M, Oliverio MI, Mannon PJ, Best CF, Maeda N, Smithies O and Coffman TM: Regulation of blood pressure by the type 1A angiotensin II receptor gene. Proc Natl Acad Sci USA 92: 3521-3525, 1995 .

4. Sadoshima J, Xu Y, Slayter HS and Izumo S: Autocrine release of angiotensin II mediates stretch-induced hypertrophy of cardiac myocytes in vitro. Cell 75: 977-984, 1993.

5. Kim S, Ohta K, Hamaguchi A, Yukimura T, Miura K and Iwao H: Angiotensin II induces cardiac phenotypic modulation and remodeling in vivo in rats. Hypertension 25: 1252-1259, 1995.

6. Mollmann H, Schmidt-Schweda S, Nef H, Möllmann S, Burstin JV, Klose S, Elsässer A and Holubarsch CJ: Contractile effects of angiotensin and endothelin in failing and non-failing human hearts. Int J Cardiol 114: 34-40, 2007.

7. Fabris B, Candido R, Bortoletto M, Zentilin L, Sandri M, Fior F, Toffoli B, Stebel M, Bardelli M, Belgrado D, et al: Dose and time-dependent apoptotic effects by angiotensin II infusion on left ventricular cardiomyocytes. J Hypertens 25: 1481-1490, 2007.

8. Guo H, Liu B, Hou L, The E, Li G, Wang D, Jie Q, Che W and Wei Y: The role of mAKAP $\beta$ in the process of cardiomyocyte hypertrophy induced by angiotensin II. Int J Mol Med 35 $1159-1168,2015$

9. Bai Y, Sun X, Chu Q, Li A, Qin Y, Li Y, Yue E, Wang H, Li G, Zahra SM, et al: Caspase-1 regulates Ang II-induced cardiomyocyte hypertrophy via up-regulation of IL-1 $\beta$. Biosci Rep: Apr 27, 2018 (Epub ahead of print)
10. Kimes BW and Brandt BL: Properties of a clonal muscle cell line from rat heart. Exp Cell Res 98: 367-381, 1976.

11. Cosens DJ and Manning A: Abnormal electroretinogram from a Drosophila mutant. Nature 224: 285-287, 1969.

12. Pak WL, Grossfield J and Arnold KS: Mutants of the visual pathway of Drosophila melanogaster. Nature 227: 518-520, 1970.

13. Hotta Y and Benzer S: Genetic dissection of the Drosophila nervous system by means of mosaics. Proc Natl Acad Sci USA 67: 1156-1163, 1970 .

14. Nilius B and Szallasi A: Transient receptor potential channels as drug targets: From the science of basic research to the art of medicine. Pharmacol Rev 66: 676-814, 2014.

15. Montell C, Birnbaumer L, Flockerzi V, Bindels RJ, Bruford EA, Caterina MJ, Clapham DE, Harteneck C, Heller S, Julius D, et al: A unified nomenclature for the superfamily of TRP cation channels. Mol Cell 9: 229-231, 2002.

16. Jiang Y, Huang H, Liu P, Wei H, Zhao H, Feng Y, Wang W and Niu W: Expression and localization of TRPC proteins in rat ventricular myocytes at various developmental stages. Cell Tissue Res 355: 201-212, 2014.

17. Mu YP, Lin DC, Yan FR, Jiao HX, Gui LX and Lin MJ: Alterations in caveolin-1 expression and receptor-operated $\mathrm{Ca} 2+$ entry in the aortas of rats with pulmonary hypertension. Cell Physiol Biochem 39: 438-452, 2016.

18. Huynh KW, Cohen MR, Chakrapani S, Holdaway HA, Stewart PL and Moiseenkova-Bell VY: Structural insight into the assembly of TRPV channels. Structure 22: 260-268, 2014.

19. Tai Y, Yang S, Liu Y and Shao W: TRPC Channels in Health and Disease. Adv Exp Med Biol 976: 35-45, 2017.

20. Kwon J, An H, Sa M, Won J, Shin JI and Lee CJ: Orail and orai3 in combination with stim 1 mediate the majority of store-operated calcium entry in astrocytes. Exp Neurobiol 26: 42-54, 2017.

21. Li N, Si B, Ju JF, Zhu M, You F, Wang D, Ren J, Ning YS, Zhang FQ, Dong K, et al: Nicotine induces cardiomyocyte hypertrophy through trpc3-mediated $\mathrm{Ca}^{2+}$ NFAT signalling pathway. Can J Cardiol 32: 1260.e1-1260.e10, 2016.

22. Antigny F, Sabourin J, Sauc S, Bernheim L, Koenig S and Frieden M: TRPC1 and TRPC4 channels functionally interact with STIM1L to promote myogenesis and maintain fast repetitive $\mathrm{Ca}^{2+}$ release in human myotubes. Biochim Biophys Acta Mol Cell Res 1864: 806-813, 2017.

23. Ambudkar IS, de Souza LB and Ong HL: TRPC1, Orai1, and STIM1 in SOCE: Friends in tight spaces. Cell Calcium 63: 33-39, 2017.

24. Pecoraro M, Pinto A and Popolo A: Mitochondria and cardiovascular disease: A Brief Account. Crit Rev Eukaryot Gene Expr 29: 295-304, 2019.

25. Yue Z, Xie J, Yu AS, Stock J, Du J and Yue L: Role of TRP channels in the cardiovascular system. Am J Physiol Heart Circ Physiol 308: H157-182, 2015

26. Eder P: Cardiac Remodeling and Disease: SOCE and TRPC Signaling in Cardiac Pathology. Adv Exp Med Biol 993: 505-521, 2017.

27. Falcón D, Galeano-Otero I, Calderón-Sánchez E, Del Toro R, Martín-Bórnez M, Rosado JA, Hmadcha A and Smani T: TRP Channels: Current perspectives in the adverse cardiac remodeling. Front Physiol 10: 159, 2019.

28. Ohba T, Watanabe H, Murakami M, Takahashi Y, Iino K, Kuromitsu S, Mori Y, Ono K, Iijima T and Ito H: Upregulation of TRPC1 in the development of cardiac hypertrophy. J Mol Cell Cardiol 42: 498-507, 2007.

29. Sunggip C, Shimoda K, Oda S, Tanaka T, Nishiyama K, Mangmool S, Nishimura A, Numaga-Tomita T and Nishida M: TRPC5-eNOS axis negatively regulates ATP-induced cardiomyocyte hypertrophy. Front Pharmacol 9: 523, 2018.

30. Kuwahara K, Wang Y, McAnally J, Richardson JA, Bassel-Duby R, Hill JA and Olson EN: TRPC6 fulfills a calcineurin signaling circuit during pathologic cardiac remodeling. J Clin Invest 116: 3114-3126, 2006

31. Satoh S, Tanaka H, Ueda Y, Oyama J, Sugano M, Sumimoto H, Mori Y and Makino N: Transient receptor potential (TRP) protein 7 acts as a $\mathrm{G}$ protein-activated $\mathrm{Ca} 2+$ channel mediating angiotensin II-induced myocardial apoptosis. Mol Cell Biochem 294: 205-215, 2007.

32. Lyon RC, Zanella F, Omens JH and Sheikh F: Mechanotransduction in cardiac hypertrophy and failure. Circ Res 116: 1462-1476, 2015.

33. Hou J and Kang YJ: Regression of pathological cardiac hypertrophy: Signaling pathways and therapeutic targets. Pharmacol Ther 135: 337-354, 2012. 
34. Li H: TRP Channel Classification. Adv Exp Med Biol 976: 1-8, 2017.

35. Sawamura S, Shirakawa H, Nakagawa T, Mori Y and Kaneko S: Frontiers in Neuroscience TRP Channels in the Brain: What Are They There For? In: Neurobiology of TRP Channels. Emir TLR (ed). 2nd edition. CRC Press/Taylor \& Francis, Boca Raton, FL, pp295-322, 2017.

36. Caterina MJ and Pang Z: TRP Channels in Skin Biology and Pathophysiology. Pharmaceuticals (Basel) 9: pii: E77, 2016.

37. Pedersen SF, Owsianik G and Nilius B: TRP channels: An overview. Cell Calcium 38: 233-252, 2005.

38. Lee HC, Yoon SY, Lykke-Hartmann K, Fissore RA and Carvacho I: TRPV3 channels mediate $\mathrm{Ca}^{2+}$ influx induced by 2-APB in mouse eggs. Cell Calcium 59: 21-31, 2016.

39. El Boustany C, Bidaux G, Enfissi A, Delcourt P, Prevarskaya N and Capiod T: Capacitative calcium entry and transient receptor potential canonical 6 expression control human hepatoma cell proliferation. Hepatology 47: 2068-2077, 2008

40. Song MY and Yuan JX: Introduction to TRP channels: Structure, function, and regulation. Adv Exp Med Biol 661: 99-108, 2010

41. Greka A, Navarro B, Oancea E, Duggan A and Clapham DE: TRPC5 is a regulator of hippocampal neurite length and growth cone morphology. Nat Neurosci 6: 837-845, 2003.

42. Lepage PK and Boulay G: Molecular determinants of TRP channel assembly. Biochem Soc Trans 35: 81-83, 2007.

43. Qi H, Ren J, E M, Zhang Q, Cao Y, Ba L, Song C, Shi P, Fu B and Sun H: MiR-103 inhibiting cardiac hypertrophy through inactivation of myocardial cell autophagy via targeting TRPV3 channel in rat hearts. J Cell Mol Med 23: 1926-1939, 2019.

44. Wang Z, Xu Y, Wang M, Ye J, Liu J, Jiang H, Ye D and Wan J: TRPA1 inhibition ameliorates pressure overload-induced cardiac hypertrophy and fibrosis in mice. EBioMedicine 36 54-62, 2018

45. Seth M, Zhang ZS, Mao L, Graham V, Burch J, Stiber J, Tsiokas L, Winn M, Abramowitz J, Rockman HA, et al: TRPC1 channels are critical for hypertrophic signaling in the heart. Circ Res 105: 1023-1030, 2009.

46. Kinoshita H, Kuwahara K, Nishida M, Jian Z, Rong X, Kiyonaka S, Kuwabara Y, Kurose H, Inoue R, Mori Y, et al: Inhibition of TRPC6 channel activity contributes to the antihypertrophic effects of natriuretic peptides-guanylyl cyclase-A signaling in the heart. Circ Res 106: 1849-1860, 2010.

47. Watanabe $\mathrm{H}$, Iino $\mathrm{K}$, Ohba $\mathrm{T}$ and Ito $\mathrm{H}$ : Possible involvement of TRP channels in cardiac hypertrophy and arrhythmia. Curr Top Med Chem 13: 283-294, 2013.
48. Eder P and Molkentin JD: TRPC channels as effectors of cardiac hypertrophy. Circ Res 108: 265-272, 2011.

49. Ding J, Xiao Y, Lu D, Du YR, Cui XY and Chen J: Effects of SKF-96365, a TRPC inhibitor, on melittin-induced inward current and intracellular $\mathrm{Ca} 2+$ rise in primary sensory cells. Neurosci Bull 27: 135-142, 2011.

50. Merritt JE, Armstrong WP, Benham CD, Hallam TJ, Jacob R, Jaxa-Chamiec A, Leigh BK, McCarthy SA, Moores KE and Rink TJ: SK\&F 96365, a novel inhibitor of receptor-mediated calcium entry. Biochem J 271: 515-522, 1990.

51. Chen KH, Liu H, Yang L, Jin MW and Li GR: SKF-96365 strongly inhibits voltage-gated sodium current in rat ventricular myocytes. Pflugers Arch 467: 1227-1236, 2015.

52. Hartman JC: The role of bradykinin and nitric oxide in the cardioprotective action of ACE inhibitors. Ann Thorac Surg 60: 789-792, 1995

53. Weber KT, Brilla CG and Janicki JS: Myocardial fibrosis: Functional significance and regulatory factors. Cardiovasc Res 27: 341-348, 1993

54. Rohini A, Agrawal N, Koyani CN and Singh R: Molecular targets and regulators of cardiac hypertrophy. Pharmacol Res 61: 269-280, 2010.

55. Onohara N, Nishida M, Inoue R, Kobayashi H, Sumimoto $H$, Sato Y, Mori Y, Nagao T and Kurose H: TRPC3 and TRPC6 are essential for angiotensin II-induced cardiac hypertrophy. EMBO J 25: 5305-5316, 2006.

56. Harada M, Luo X, Qi XY, Tadevosyan A, Maguy A, Ordog B, Ledoux J, Kato T, Naud P, Voigt N, et al: Transient receptor potential canonical-3 channel-dependent fibroblast regulation in atrial fibrillation. Circulation 126: 2051-2064, 2012.

57. Gao H, Wang F, Wang W, Makarewich CA, Zhang H, Kubo H, Berretta RM, Barr LA, Molkentin JD and Houser SR: Ca(2+) influx through L-type $\mathrm{Ca}(2+)$ channels and transient receptor potential channels activates pathological hypertrophy signaling. J Mol Cell Cardiol 53: 657-667, 2012.

58. Singh A, Hildebrand ME, Garcia E and Snutch TP: The transient receptor potential channel antagonist SKF96365 is a potent blocker of low-voltage-activated T-type calcium channels. Br J Pharmacol 160: 1464-1475, 2010.

This work is licensed under a Creative Commons Attribution-NonCommercial-NoDerivatives 4.0 International (CC BY-NC-ND 4.0) License. 